\title{
Isolated pulmonary artery arising from a duct: A single-center review of diagnostic and therapeutic strategies
}

\author{
Sarosh P. Batlivala, MD, ${ }^{\mathrm{a}, \mathrm{c}, \mathrm{e}, \mathrm{f}}$ Doff B. McElhinney, MD, ${ }^{\mathrm{a}, \mathrm{c}}$ Frank A. Pigula, MD, ${ }^{\mathrm{b}, \mathrm{d}}$ and \\ Audrey C. Marshall, MD ${ }^{\mathrm{a}, \mathrm{c}}$
}

Objective: Isolated pulmonary artery of ductal origin (IPADO) is a rare disease with diverse presentations. Diagnostic and therapeutic approaches vary widely given the low incidence. Reporting additional cases may help inform medical decision making.

Methods: We reviewed diagnostic data—including echocardiography, catheterization, and MRI—and outcomes for all patients with IPADO at our institution.

\begin{abstract}
Results: Thirty-seven patients who met inclusion criteria were identified. The mean age at diagnosis was 3 months (range, 1 day-45 years). In 11 patients, the duct supplying the IPADO was patent (ie, patent ductus arteriosis [PDA]); the duct had closed (ligamentum) in the other 26 patients. When performed, catheterization delineated the anatomy in $90 \%(100 \%$ if PDA) versus $54 \%$ with magnetic resonance imaging. Patients with a PDA were more likely to undergo intervention $(100 \%$ vs $58 \%, P=.02)$ and had earlier first intervention ( 1 vs 20 months; $P<.001)$. Patients diagnosed at age $\leq 6$ months were more likely to undergo intervention ( $86 \%$ vs $50 \% ; P=.03)$ and unifocalization $(81 \%$ vs $44 \% ; P=.04)$, and had greater IPADO flow at follow-up $(40 \%$ vs $14 \% ; P<.001)$. Patients who underwent any intervention had greater IPADO flow than those without intervention ( $38 \%$ vs $0 \%)$.

Conclusions: Early IPADO diagnosis is important in long-term outcome. However, successful interventions can be performed on older patients. Diagnosis relies on angiography but magnetic resonance imaging may play an increasingly important role. Although initial intervention depends on individual factors, the ultimate goal should be early unifocalization. (J Thorac Cardiovasc Surg 2014;148:2245-52)
\end{abstract}

Ductal origin of a pulmonary artery (PA) is a rare condition. Fraentzel $^{1}$ published the first description of "a case of abnormal communication of the aorta with the pulmonary artery" in 1868. It is commonly associated with other congenital heart diseases-mostly tetralogy of Fallot and truncus arteriosus-with a prevalence up to $0.4 \% .^{2}$ This lesion occurs in isolation as well, with an estimated incidence of $\sim 1: 200,000$. $^{3}$

When in isolation, this lesion is often described as a unilaterally "absent" PA, but we prefer isolated PA of ductal origin (IPADO), the descriptor used by Takatsuki and colleagues. ${ }^{4}$ Although the extrapulmonary portion of the PA is missing, the intrapulmonary vessels are present and generally branch normally, suggesting the anomaly is related to a specific embryologic disruption involving involution of the proximal sixth aortic $\operatorname{arch}^{5-8}$ However, a

\footnotetext{
From the Departments of Cardiology ${ }^{\mathrm{a}}$ and Cardiac Surgery, ${ }^{\mathrm{b}}$ Boston Children's Hospital, Boston, Mass; Departments of Pediatrics ${ }^{\mathrm{c}}$ and Surgery, ${ }^{\mathrm{d}}$ Harvard Medical School, Boston, Mass; Division of Pediatric Cardiology, ${ }^{\mathrm{e}}$ Batson Children's Hospital, Jackson, Miss; and Department of Pediatrics, ${ }^{\mathrm{f}}$ University of Mississippi Medical Center, Jackson, Miss.

Disclosures: Authors have nothing to disclose with regard to commercial support.

Received for publication Sept 13, 2013; revisions received Nov 7, 2013; accepted for publication Nov 22, 2013; available ahead of print Feb 9, 2014.

Address for reprints: Sarosh P. Batlivala, MD, Pediatric Cardiology, Batson Children's Hospital, Jackson, MS 39216 (E-mail: sbatlivala@umcedu). $0022-5223 / \$ 36.00$

Copyright (C) 2014 by The American Association for Thoracic Surgery http://dx.doi.org/10.1016/j.jtcvs.2013.11.047
}

connection persists between the intrapulmonary PA, which arises from the respective lung bud, and the distal sixth aortic arch, which develops into the ductus arteriosus. ${ }^{8,9}$ The result is an intrapulmonary PA that is discontinuous from the central pulmonary circulation and fed directly by a ductus arteriosus (Figure 1).

IPADO presents in myriad ways, including recurrent infection, hemoptysis, pulmonary arterial hypertension (PAH), congestive heart failure, and scoliosis; it affects some patients severely at young ages, whereas others are asymptomatic with serendipitous diagnosis in adulthood. ${ }^{10-12}$ Such heterogeneity has been associated with variable approaches to management. Treatment strategies include insertion of a surgical shunt to promote IPADO growth before unifocalization into the pulmonary circulation, unifocalizing the IPADO initially, or performing an interventional catheterization before a surgical intervention. ${ }^{13-16}$

Our aim was to provide data to help inform decision making given this variation in practice. Although the incidence of IPADO is insufficient to provide conclusive data, we attempted to identify potentially relevant diagnostic and therapeutic variables.

\section{PATIENTS AND METHODS \\ Patients}

We performed a retrospective, single-center cohort study of all patients with IPADO cared for at Boston Children's Hospital. We included patients with a patent foramen ovale, secundum atrial septal defect, or ventricular 


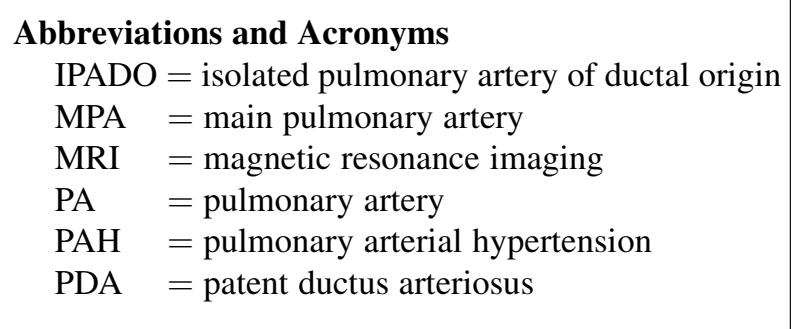

septal defect that was deemed hemodynamically insignificant (ie, pressure restrictive, no volume overload, and no intervention). Patients with a patent ductus arteriosus (PDA) were also included given the integral relationship between the ductus and IPADO. Exclusion criteria were cardiovascular lesions other than above, agenesis or severe hypoplasia of the ipsilateral lung, and iatrogenic discontinuity of a PA (eg, after PDA ligation). Our study was performed under a protocol approved by the Children's Hospital Committee for Clinical Investigation, which included a waiver for requiring patient consent.

\section{Definitions and Outcomes}

Nearly all patients underwent postoperative transthoracic echocardiography and many underwent nuclear scintigraphy lung perfusion and cardiac magnetic resonance imaging (MRI) scans. All studies were performed for clinical indications at the treating physician's discretion. All data were obtained from existing clinical records, with thorough attempts to obtain the most recent data for patients treated outside our institution.

No study end points were defined a priori and the most recent data were used for all patients. Study points of interest included age at first presentation and correct diagnosis, initial diagnosis or misdiagnosis, preoperative catheterization or cardiac MRI (if performed), age at first intervention, number and type of interventions (surgical: shunt or unifocalization; transcatheter: angioplasty or stenting), serious postprocedural complications, death, and duration of follow-up. Serious postprocedural complications included intra- or perioperative death and requirement for reintervention within 15 days.

A shunt was defined as a surgically created connection between the IPADO and systemic arterial system. Unifocalization was defined as a connection of the IPADO to the PA circulation and further classified as direct or with a tube graft. Direct unifocalization was anastomosis of the IPADO directly to the main pulmonary artery (MPA), including use of an MPA flap or noncircumferential piece of material to augment the anastomosis. A tube graft was a fully circumferential tube of any material interposed between the IPADO and MPA.

Study measures of interest included symptoms, history of PAH, treatment with anti-PAH medications, initial and most recent percentage of flow to the IPADO, and initial and most recent IPADO cross-sectional area (indexed to body surface area). Two orthogonal measurements were used to calculate cross-sectional area when available. PAH was defined as a directly measured mean pressure $\geq 25 \mathrm{~mm} \mathrm{Hg}$ in the PA continuous with the right ventricle. If catheterization data were not available, PAH was defined as an estimated right ventricle pressure $\geq 50 \%$ systemic by echocardiographic measures. Catheterization and MRI adequately delineated anatomy if at least 1 IPADO diameter and the distance from IPADO to MPA were reliably measured.

\section{Data Analysis}

Data are presented as median (range) or frequency ( $\%$ of appropriate cohort). Demographic, historical, diagnostic, and procedural variables were compared between the cohorts. To detect associations, the population was divided into 3 groups for comparisons: those who underwent any intervention or not, status of the IPADO-supplying duct at presentation (PDA or ligamentum arteriosum), and age at presentation ( $\leq 6$ vs $>6$ months $)$. The $\chi^{2}$ or Fisher exact test were used to compare nominal variables between 2 or more groups. The Mann-Whitney $U$ and Kruskal-Wallis tests were used to compare medians between 2 or more groups. All data analyses and the standard scatter plots were created using Statistical Package for the Social Sciences software (version 19, IBM-SPSS Inc, Armonk, NY).

\section{RESULTS \\ Patients}

We identified 49 patients with an IPADO managed at Boston Children's Hospital from July 1951 through September 2011; 12 were excluded due to agenesis of the ipsilateral lung or an iatrogenic IPADO. Demographic and diagnostic variables of all patients are presented in Table 1. Most patients presented in infancy with respiratory symptoms, a murmur, or cyanosis. Two-thirds of the cohort was diagnosed after 2000 . Five patients were initially misdiagnosed; 2 were correctly diagnosed within 6 months, whereas 3 were diagnosed 2, 3, and 20 years after presentation. All patients had an IPADO contralateral to aortic sidedness, in keeping with the postulated etiology. ${ }^{8}$ Median duration of follow-up data was 7.3 years.

Of 37 patients included in our study, 26 had an IPADO connected to a ligamentum arteriosum, whereas 11 were supplied by a PDA. Patients with a PDA presented earlier (0.6 vs 4.3 months; $P=.04$ ) and with shorter duration from presentation to diagnosis (0.03 vs 1.6 months; $P<.001)$ than those with a ligamentum. More than half of patients with a ligamentum presented with respiratory symptoms, whereas most with a PDA presented with a murmur or cyanosis. All patients presenting with hemoptysis had a ligamentum. Ductal status was not associated with era (ie, diagnosis before or after January 1, 2000).

Twenty-one patients were diagnosed before age 6 months. Younger patients presented roughly equally with respiratory symptoms, a murmur, or cyanosis, whereas most older patients presented with respiratory symptoms. No older patient presented with cyanosis. Both patients with hemoptysis presented at older age (20 and 70 months). Approximately $45 \%$ of younger patients had a PDA versus only $12 \%$ of older patients. Younger patients were also correctly diagnosed sooner after presentation (0.1 vs 4.8 months; $P<.001)$ and had greater flow to the IPADOsupplied lung initially (33\% vs $0 \% ; P<.001)$ (Figure 2$)$.

\section{Diagnostic Studies}

Nine PDA patients and 18 ligamentum patients underwent preoperative catheterization. Catheterization adequately delineated the anatomy in all cases with a PDA, but in only 12 with a ligamentum; pulmonary vein wedge angiograms were performed in all patients. Three PDA patients and 10 ligamentum patients had a preoperative MRI. MRI adequately delineated anatomy in 1 PDA patient 


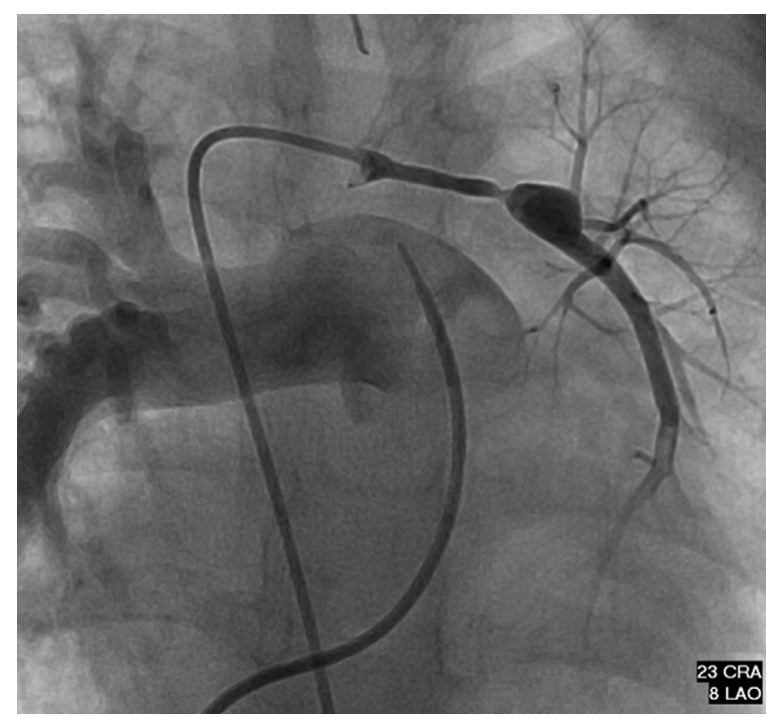

FIGURE 1. Simultaneous injections into a left isolated pulmonary artery of ductal origin (IPADO) and right pulmonary artery. The right pulmonary artery catheter courses antegrade through the right ventricle, whereas the left IPADO catheter ascends retrograde from the right-sided aorta into the left patent ductus arteriosus.

and 6 ligamentum patients. No MRI defined the anatomy when catheterization failed to do so.

\section{Therapeutic Strategies}

Demographic, diagnostic, and therapeutic variables based on initial intervention are presented in Table 2 . Twenty-six patients underwent at least 1 IPADO intervention; all ultimately underwent surgery. Eight patients had initial shunt placement, whereas 18 had initial unifocalization. One of the shunt patients had initial transcatheter intervention (PDA stent) with subsequent shunt palliation. Another patient remains with a shunt with the plan to unifocalize; both patients currently with shunts have a leftsided IPADO. The other 6 initial shunt patients underwent subsequent unifocalization, all of which were with a tube graft. Patients who had an initial unifocalization were younger and underwent operation earlier than those with initial shunt (Figure 3). Those patients also had fewer surgical interventions and fewer procedures overall.

Among unifocalized patients, 13 underwent direct unifocalization and 11 had tube grafts. The direct unifocalization group was younger at diagnosis (0.7 vs 14 months; $P=.001)$ and first intervention (1 vs 20 months; $P=.003)$. The direct unifocalization group had fewer total ( 2 vs $4 ; P=.01$ ) and surgical ( 1 vs $2 ; P=.01)$ interventions with more flow at most-recent follow-up ( $40 \%$ vs $32 \%)$.

\section{Reinterventions}

A total of 40 postoperative interventions were performed on 19 patients. Those procedures included 23 balloon angioplasties, 6 angioplasties with stent placement, and 11 operations. All 8 shunt patients had a postoperative intervention; 5 of the 8 had a first reintervention related to issues with the shunt (ie, anastomotic stenosis or shunt thrombosis), whereas 3 had unifocalization at first reintervention. Of the 18 patients initially unifocalized, 7 had no reinterventions. Among the 11 with reinterventions, 1 had a reoperation for acute thrombosis of a unifocalized tube graft and 10 patients only had catheter-based reinterventions. The median duration to first reintervention was longer in the initially unifocalized group (5 vs 2.4 months) with fewer reinterventions performed per subject (1 vs 2 ).

\section{Outcomes}

All patients with a PDA underwent an intervention versus only $58 \%$ of patients with a ligamentum. Younger patients had greater IPADO flow at recent measurement $(40 \%$ vs $14 \% ; P<.001)$. Younger patients were also more likely to undergo intervention ( $86 \%$ vs $50 \%$ ) and to undergo ultimate unifocalization ( $81 \%$ vs $44 \%$ ) (Figure 2).

Among 16 patients who presented after age 10 months, 8 underwent intervention. Patients who underwent intervention were younger (median 31 vs 165 months; $P=.03$ ), the oldest of whom was diagnosed at 83 months. Of these 8,2 had a PDA and 6 had a ligamentum. One of the patients with a PDA had direct unifocalization and had an increase in IPADO flow from $0 \%$ to $16 \%$. The other patient with a PDA underwent initial catheter-based PDA stenting followed by shunt placement; the shunt thrombosed, no subsequent interventions were performed, and there was no flow to the IPADO at most recent follow-up. Two patients with a ligamentum were initially unifocalized with increases in flow from $0 \%$ to $28 \%$ and $30 \%$. The other 4 patients had initial shunt placement followed by unifocalization; 1 had a minimal increase in flow but 2 had final indexed IPADO flows of $14 \%$ and $15 \%$ and the other had an increase in IPADO area from 12 to $40 \mathrm{~mm}^{2} / \mathrm{m}^{2}$.

\section{Complications}

Four patients experienced serious postoperative complications: 3 had thrombosis of a shunt and 1 had thrombosis of a unifocalization tube graft. Two of the shunts were completely occluded and replaced; 1 was restored with thrombectomy. The shunt thrombectomy patient had partial thrombosis, significant lung disease with PAH, and died shortly after. Of the 2 patients with complete shunt occlusion, 1 had the smallest indexed cross-sectional area of the entire cohort and the other was well below the median. The patient with tube graft thrombosis underwent graft replacement on postoperative day 5 with no further complications.

Three known deaths occurred that were related, at least in part, to the IPADO. Two had been correctly diagnosed initially, but both patients were born prematurely with significant lung disease. One died from sepsis in infancy and 
TABLE 1. Demographic, diagnostic, and follow-up data for the entire population and by cohort

\begin{tabular}{|c|c|c|c|c|}
\hline & All patients $(\mathbf{N}=\mathbf{3 7})$ & Any intervention $(n=26)$ & No intervention $(\mathrm{n}=11)$ & $P$ value* \\
\hline \multicolumn{5}{|l|}{ Discontinuous PA } \\
\hline Left & $17(46 \%)$ & $12(46 \%)$ & $5(45 \%)$ & \\
\hline Right & $20(54 \%)$ & $14(54 \%)$ & $6(55 \%)$ & \\
\hline Age at diagnosis, mo & $3.2(0-539)$ & $2.4(0-83.5)$ & $66.2(0.1-539)$ & .01 \\
\hline Era of diagnosis & & & & .008 \\
\hline Before January 1, 2000 & $12(32 \%)$ & $5(19 \%)$ & $7(64 \%)$ & \\
\hline On or after January 1, 2000 & $25(68 \%)$ & $21(81 \%)$ & $4(36 \%)$ & \\
\hline \multicolumn{5}{|l|}{ Sex } \\
\hline Male & $15(41 \%)$ & $11(42 \%)$ & $4(36 \%)$ & \\
\hline Female & $22(49 \%)$ & $15(58 \%)$ & $7(64 \%)$ & \\
\hline Status of duct at diagnosis & & & & .01 \\
\hline Patent & $11(30 \%)$ & $11(42 \%)$ & $0(0 \%)$ & \\
\hline Ligamentum & $26(70 \%)$ & $15(58 \%)$ & $11(100 \%)$ & \\
\hline Age of presenting complaint, mo & $2.3(0-516)$ & $1.5(0-69)$ & $5.2(0-516)$ & \\
\hline \multicolumn{5}{|l|}{ Presenting symptom/sign } \\
\hline Respiratory symptoms & $15(41 \%)$ & $10(38 \%)$ & $5(45 \%)$ & \\
\hline Murmur & $10(27 \%)$ & $7(27 \%)$ & $3(27 \%)$ & \\
\hline Cyanosis & $6(16 \%)$ & $4(15 \%)$ & $2(18 \%)$ & \\
\hline Hemoptysis & $2(5 \%)$ & $2(8 \%)$ & $0(0 \%)$ & \\
\hline Other $\dagger$ & $4(11 \%)$ & $3(12 \%)$ & $1(9 \%)$ & \\
\hline Initial misdiagnoses & $5(14 \%)$ & $2(8 \%)$ & $3(27 \%)$ & \\
\hline Time from presentation to diagnosis, mo & $1(0-244)$ & $0.4(0-34)$ & $3.4(0.1-244)$ & .01 \\
\hline \multicolumn{5}{|l|}{ Right ventricular hypertension } \\
\hline At time of diagnosis & $19(51 \%)$ & $11(42 \%)$ & $8(73 \%)$ & \\
\hline Ever & $22(59 \%)$ & $14(52 \%)$ & $8(73 \%)$ & \\
\hline At most recent follow-up & $8(22 \%)$ & $1(4 \%)$ & $7(64 \%)$ & $<.001$ \\
\hline \multicolumn{5}{|l|}{ Pulmonary antihypertensive medications } \\
\hline Ever & $4(11 \%)$ & $2(8 \%)$ & $2(18 \%)$ & \\
\hline At most recent follow-up & $2(5 \%)$ & $1(4 \%)$ & $1(9 \%)$ & \\
\hline Symptoms at most recent follow-up & $6(16 \%)$ & $2(8 \%)$ & $4(36 \%)$ & .03 \\
\hline Age at first intervention, mo & & $4.5(0.1-91.6)$ & NA & \\
\hline \multicolumn{5}{|l|}{ First intervention type } \\
\hline Surgical & & $25(96 \%)$ & NA & \\
\hline Transcatheter & & $1(4 \%)$ & NA & \\
\hline \multicolumn{5}{|l|}{ First operation } \\
\hline Shunt & & $8(31 \%)$ & NA & \\
\hline Unifocalization & & $18(69 \%)$ & NA & \\
\hline Total interventions & & $2(1-6)$ & NA & \\
\hline Total surgical interventions & & $1(1-3)$ & NA & \\
\hline Ultimately unifocalized & & $24(92 \%)$ & NA & \\
\hline Age at unifocalization, mo & & $4.9(0.1-97)$ & NA & \\
\hline \multicolumn{5}{|l|}{ Initial IPADO cross-sectional area } \\
\hline Indexed, $\mathrm{mm}^{2} / \mathrm{m}^{2}$ & $17.5(0-69.1)$ & $24.6(6.6-69.1)$ & $0(0-5)$ & $<.001$ \\
\hline \multicolumn{5}{|l|}{ Most recent IPADO cross-sectional area } \\
\hline Indexed, $\mathrm{mm}^{2} / \mathrm{m}^{2}$ & $50.6(0-189)$ & $53.3(23.7-189)$ & $0(0-0)$ & .1 \\
\hline First flow distribution to IPADO, $\%$ & $11(0-59)$ & $15(0-59)$ & $0(0-1)$ & .04 \\
\hline Most recent flow distribution to IPADO, \% & $34(0-59)$ & $38(0-59)$ & $0(0-1)$ & .008 \\
\hline Duration of follow-up, y & $7.3(0.1-59)$ & $7.4(0-20)$ & $6.5(2-59)$ & \\
\hline
\end{tabular}

Data are presented as median (range) or frequency (\%). PA, Pulmonary artery; $N A$, not applicable; IPADO, isolated pulmonary artery of ductal origin. *Comparing any intervention and no intervention cohorts. †Other diagnoses include abnormal chest radiograph, electrocardiogram, and screening obstetric ultrasound.

the other was the patient who experienced partial postoperative shunt occlusion. The third patient was diagnosed with IPADO at age 44 years after an MRI, and ultimately died from heart failure related to $\mathrm{PAH}$ at age 60 years.

\section{DISCUSSION}

\section{Importance of Age at Intervention and Outcome}

Many studies have suggested that early diagnosis and management of patients with IPADO is important. ${ }^{17-20}$ 

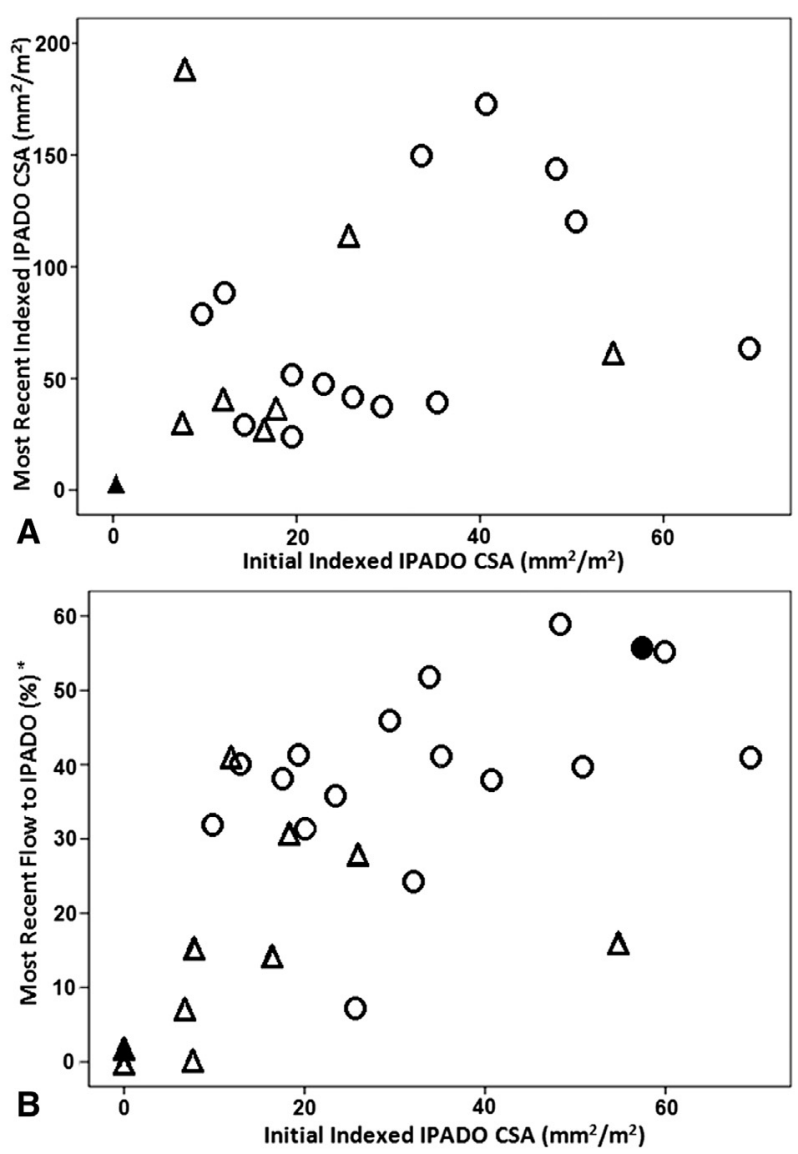

$O=$ Diagnosed at $<6$ months
$\Delta=$ Diagnosed at $\geq 6$ months

No fill = Normal RV pressure, most recent follow-up $\operatorname{CS} A=$ cross sectional area $m m=$ millimeter $m=$ meter

*\% flow to IPADO expressed as Solid fill = RV hypertension, most recent follow-up

FIGURE 2. Scatter plots comparing first measured indexed isolated pulmonary artery of ductal origin $(I P A D O)$ cross-sectional area $(C S A)$. A, Most recent indexed IPADO CSA. B, Most recent flow to the IPADO based on age and presence of right ventricle $(R V)$ hypertension at most recent follow-up. Circles indicate diagnosed at age $<6 \mathrm{mo}$, triangles indicate diagnosed at age $\geq 6$ mo. No fill indicates normal right ventricle pressure at most recent follow-up, solid fill indicates right ventricle hypertension at most recent follow-up. *Percent flow to IPADO is expressed as percent of total pulmonary blood flow.

We believe that unifocalization and achievement of pulmonary flow distribution as close to normal as possible should be the primary treatment goals. In our cohort, patients diagnosed earlier were more likely to undergo unifocalization, suggesting that age at diagnosis is important. Interestingly, we did not observe an association between age and the total number of interventions performed. This may be due to the heterogeneity in presentation and therapeutic strategies. Also, older patients may have vascular disease in the affected lung, precluding aggressive attempts to rehabilitate the IPADO. We also did not observe differences in complication rates

between cohorts based on age, suggesting the risk of intervention is not necessarily greater in younger patients. Most patients, even those diagnosed after age 10 months, had reasonable improvement in IPADO flow and area, especially when unifocalized. Overall, we believe that diagnosis and intervention before age 6 months should be a primary goal, but that patients of any age can yield benefit from unifocalization.

\section{Associations With Initial Ductal Status}

Our data demonstrate that patients with a PDA have potential advantages compared with those in whom the ductus has closed. Patients with a PDA presented at an earlier age and were diagnosed more rapidly; 9 of 11 were diagnosed before age 4 months and 5 were diagnosed as neonates (the oldest patient was aged 49 months and an outlier). This association of age and ductal status may be related to the fact that many PDA patients presented with murmurs in early infancy, likely leading to evaluation by a pediatric cardiologist. Also, fewer PDA patients presented with recurrent respiratory symptoms or infections compared with patients with a ligamentum. This nonspecific presentation may have led to more extensive evaluation in ligamentum patients before referral to a cardiologist, prolonging time to diagnosis. In fact, half the ligamentum patients were diagnosed after 1 year, with the oldest diagnosed at nearly 45 years of age; again, ductal status was not associated with era of diagnosis. We further speculate that this later diagnosis may be related to the development of hemoptysis. Although hemoptysis is incompletely understood in patients with congenital cardiac disease, prolonged diagnosis may lead to the development of increased pulmonary vascular resistance and systemic-to-pulmonary collaterals that may play a role in this phenomenon..$^{10,21,22}$ Several studies have described the deleterious consequences of a delay in diagnosis. ${ }^{17,23}$ Our data corroborate this, because nearly one-third of patients with a ligamentum had PAH at most recent follow-up.

\section{Therapeutic Strategies}

Therapeutic strategies in this series fell into 2 basic approaches: shunt placement followed by direct unifocalization and direct unifocalization initially. ${ }^{24}$ Krammoh and colleagues ${ }^{16}$ espoused a variant of the first strategy, recommending initial stenting of the PDA supplying the IPADO with subsequent unifocalization. They hypothesized that increased flow would improve the technical feasibility and success of unifocalization. They believed this was especially useful in patients with hypoplastic branch PAs, because small PAs lead to greater pulmonary vascular resistance with a higher propensity for thrombosis of a surgical shunt. Conversely, other authors have postulated that the optimal strategy is direct unifocalization as early as 
TABLE 2. Demographic, diagnostic, and follow-up data based on initial surgical intervention

\begin{tabular}{|c|c|c|c|}
\hline Variable & Shunt $(\mathbf{n}=8)$ & Unifocalization $(n=18)$ & $P$ value \\
\hline \multicolumn{4}{|l|}{ Discontinuous PA } \\
\hline Left & $5(62.5 \%)$ & $11(61 \%)$ & \\
\hline Right & $3(37.5 \%)$ & $7(39 \%)$ & \\
\hline Age at diagnosis, mo & $22.9(1.5-83.5)$ & $0.8(0-49.9)$ & .001 \\
\hline Era of diagnosis & & & .13 \\
\hline Before January 1, 2000 & $0(0 \%)$ & $5(28 \%)$ & \\
\hline On or after January 1,2000 & $8(100 \%)$ & $13(72 \%)$ & \\
\hline Status of duct at diagnosis & & & .23 \\
\hline Patent & $2(25 \%)$ & $9(50 \%)$ & \\
\hline Ligamentum & $6(75 \%)$ & $9(50 \%)$ & \\
\hline \multicolumn{4}{|l|}{ Right ventricular hypertension } \\
\hline At time of diagnosis & $1(17 \%)$ & $10(56 \%)$ & \\
\hline Ever & $3(50 \%)$ & $11(61 \%)$ & \\
\hline At most recent follow-up & $0(0 \%)$ & $1(6 \%)$ & \\
\hline \multicolumn{4}{|l|}{ First intervention } \\
\hline Surgery & $7(87.5 \%)$ & $18(100 \%)$ & \\
\hline Catheterization & $1(12.5 \%)$ & $0(0 \%)$ & \\
\hline Age at first operation, mo & $35.5(2.8-91.6)$ & $2.4(0.1-58.1)$ & .003 \\
\hline Subsequent unifocalization & $6(75 \%)$ & NA & \\
\hline Time from shunt to unifocalization & $5.6(2.6-28.3)$ & NA & \\
\hline Any intervention(s) after first operation & $8(100 \%)$ & $11(61 \%)$ & .048 \\
\hline \multicolumn{4}{|l|}{ Total interventional catheterizations per patient } \\
\hline Balloon dilation & $1.5(0-2)$ & $1(0-3)$ & \\
\hline Stent placement & $0(0-0)$ & $0(0-2)$ & \\
\hline Duration from surgery to first reintervention, mo & $2.4(0.1-5.5)$ & $5(0.2-46.7)$ & .07 \\
\hline Total surgical interventions per patient & $2(1-3)$ & $1(1-3)$ & $<.001$ \\
\hline Total interventions per patient & $3.5(2-5)$ & $2(1-4)$ & .02 \\
\hline Age at unifocalization, mo & $39(10.4-97)$ & $2.4(0.1-58.1)$ & .001 \\
\hline \multicolumn{4}{|l|}{ Initial IPADO cross-sectional area } \\
\hline Indexed, $\mathrm{mm}^{2} / \mathrm{m}^{2}$ & $13.2(6.6-26)$ & $32.9(9.5-69.1)$ & .14 \\
\hline Most recent IPADO cross-sectional area & & & $<.001$ \\
\hline Indexed, $\mathrm{mm}^{2} / \mathrm{m}^{2}$ & $40.1(25.2-189)$ & $71.7(23.7-171.4)$ & \\
\hline First flow distribution to IPADO, $\%$ & $7(0-41)$ & $22(0-59)$ & .25 \\
\hline Most recent flow distribution to IPADO, $\%$ & $14(0-41)$ & $40(16-59)$ & $<.001$ \\
\hline Duration of follow-up, y & $4.2(0.9-10.4)$ & $8.5(0.1-20)$ & \\
\hline
\end{tabular}

Data are presented as median (range) or frequency (\%). PA, Pulmonary artery; NA, not applicable; IPADO, isolated pulmonary artery of ductal origin.

possible, followed by transcatheter intervention(s) to augment IPADO growth. ${ }^{18}$

Patients who underwent initial unifocalization in our cohort had superior outcomes (Figure 4). Multiple factors may explain this observation, some of which may be related to intrinsic pathophysiology and others to the specific therapy. One issue is that patients who underwent shunt placement were older and more likely to have a ligamentum. It is plausible that those patients had more hypoplastic or dysplastic pulmonary vasculature, impeding flow and growth of the IPADO. Earlier unifocalization should best restore normal PA physiology and may allow the IPADO and distal vasculature to match somatic growth.

It has been hypothesized that unifocalization technique is relevant. ${ }^{25,26}$ Our data suggest that patients with direct unifocalization have superior outcomes to those with an interposition graft. Other authors have described this association. ${ }^{18,19}$ One explanation is that tube grafts do not grow, thereby impeding flow, IPADO growth, and normal vascular arborization in the long term. They may also require more PA interventions to maintain optimal IPADO growth. However, 9 of 11 tube graft patients had a ligamentum and all had initial shunt placement, possibly confounding this association. Overall, we believe that direct unifocalization is the preferred therapeutic goal.

\section{Direct Angiography Versus MRI}

The diagnostic standard for defining IPADO anatomy has been angiography. As its role increases, MRI's ability to delineate anatomy has been questioned, especially if the duct is atretic or closing. ${ }^{27}$ Other authors have argued that evolving imaging techniques address this issue. ${ }^{28}$ Our data confirm that angiography can delineate the anatomy, especially if the duct is patent. Although not $100 \%$ sensitive, pulmonary venous wedge angiography is 


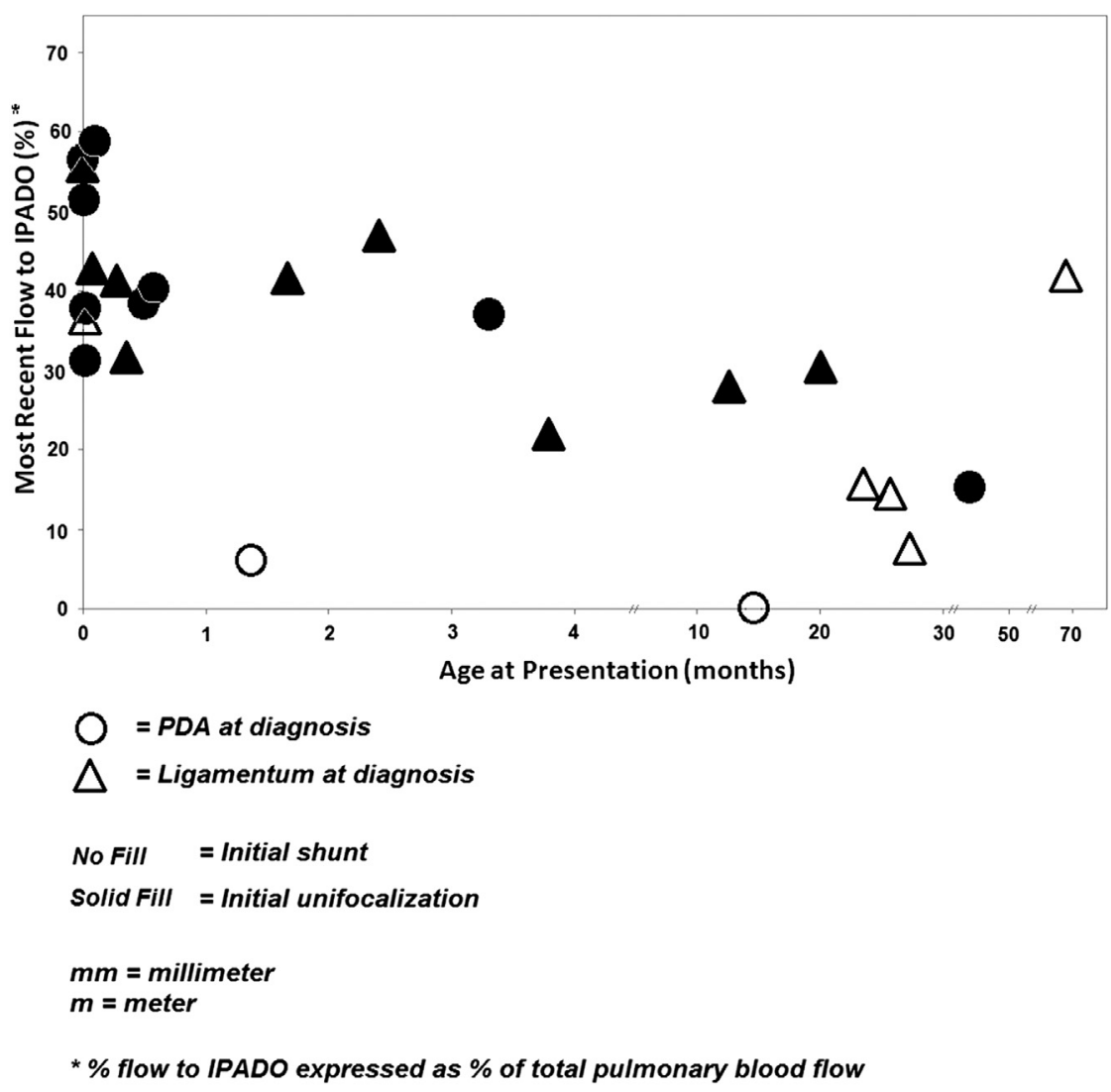

FIGURE 3. Scatter plot comparing age at presentation and most recent flow to the isolated pulmonary artery of ductal origin (IPADO) based on initial operation and status of the IPADO at diagnosis. Circles indicate patent ductus arteriosus (PDA) at diagnosis, triangles indicate ligamentum at diagnosis. No fill indicates initial shunt, solid fill indicates initial unifocalization. *Percent flow to IPADO is expressed as percent of total pulmonary blood flow.

necessary to delineate anatomy in cases with a ligamentum. MRI failed to delineate the anatomy when catheterization was unsuccessful in our experience. However, MRI delineated the anatomy in $60 \%$ of patients with a ligamentum. Although our sample size is small, the utility of MRI in patients with ligamentum should not be overlooked.

\section{Limitations}

Our study has numerous limitations. It was a retrospective, single center study with a small sample size. In addition, there was significant heterogeneity in diagnostic and therapeutic strategies. Furthermore, no strict criteria were developed. Lastly, we had limited statistical capability so

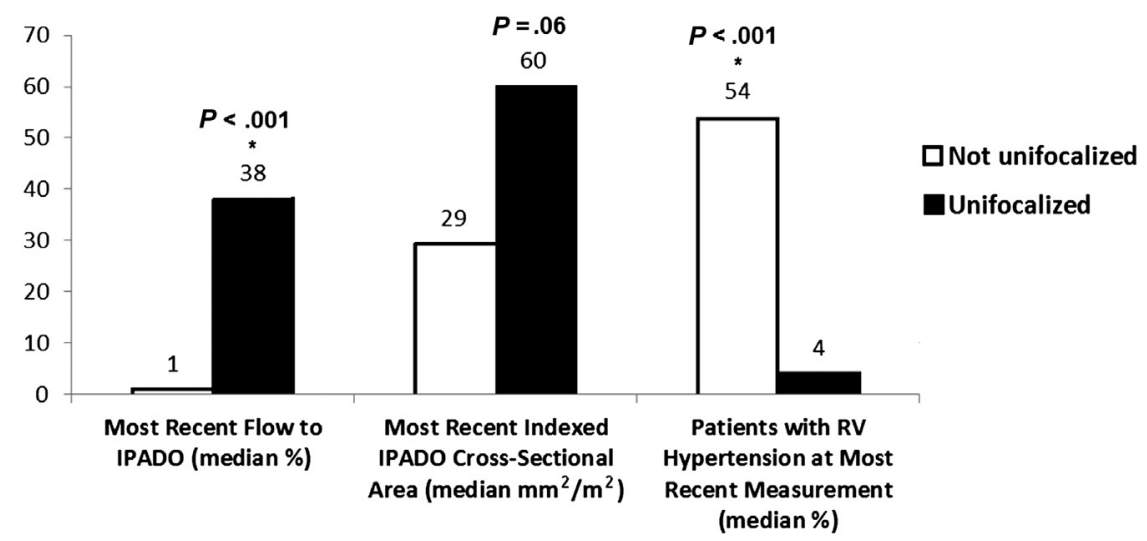

FIGURE 4. Bar graphs comparing patients who underwent unifocalization versus those who did not. *Significant $P$ value. IPADO, Isolated pulmonary artery of ductal origin; $R V$, right ventricle. 
age, PDA, era, and other variables had potentially confounding effects.

\section{CONCLUSIONS}

IPADO is a rare condition that presents in a variety of ways, with significant consequences, including impaired lung growth, PAH, and hemoptysis. Early diagnosis and intervention appear to be important to optimize longterm outcomes. We recommend a therapeutic strategy with initial catheterization or MRI to adequately delineate the anatomy and the ultimate goal of IPADO unifocalization as early as possible. A preceding procedure to increase flow to the IPADO may be warranted, but should be undertaken cautiously in patients with a small IPADO or PAH. Close follow-up with transcatheter interventions to augment IPADO growth as indicated may lead to optimal outcomes.

\section{References}

1. Fraentzel O. Ein Fall yon abnormer Communication der Aorta mit der Arteria pulmonalis. Virchows Arch Path Anat. 1868;42:420-6.

2. Kucera V, Fiser B, Tůma S, Hucin B. Unilateral absence of pulmonary artery: a report on 19 selected clinical cases. Thorac Cardiovasc Surg. 1982;30:152-8.

3. Bouros D, Pare P, Panagou P, Tsintiris K, Siafakas N. The varied manifestation of pulmonary artery agenesis in adulthood. Chest. 1995;108:670-6.

4. Takatsuki S, Darst JR, Das BB, Fagan TE, Wolfe R, Ivy DD. Clinical manifestations and long-term follow-up in pediatric patients living at altitude with isolated pulmonary artery of ductal origin. Pediatric Cardiol. 2012;33:775-81.

5. Kruzliak P, Syamasundar RP, Novak M, Pechanova O, Kovacova G. Unilateral absence of pulmonary artery: pathophysiology, symptoms, diagnosis and current treatment. Arch Cardiovasc Dis. 2013;106:448-54.

6. Alison M, Garel L, Bigras J-L, Déry J, Lapierre C. Unilateral absence of pulmonary artery in children: bronchovascular anatomy, natural course and effect of treatment on lung growth. Pediatr Radiol. 2010;41:459-68.

7. Sotomora RF, Edwards JE. Anatomic identification of so-called absent pulmonary artery. Circulation. 1978;57:624-33.

8. Apostolopoulou SC, Kelekis NL, Brountzos EN, Rammos S, Kelekis DA. "Absent" pulmonary artery in one adult and five pediatric patients: imaging, embryology, and therapeutic implications. AJR Am J Roentgenol. 2002;179:1253-60.

9. Pfefferkorn JR, Löser H, Pech G, Toussaint R, Hilgenberg F. Absent pulmonary artery. A hint to its embryogenesis. Pediatr Cardiol. 1982;3:283-6.

10. Ten Harkel ADJ, Blom NA, Ottenkamp J. Isolated unilateral absence of a pulmonary artery: a case report and review of the literature. Chest. 2002;122:1471-7.
11. Griffin N, Mansfield L, Redmond KC, Dusmet M, Goldstraw P, Mittal TK, et al. Imaging features of isolated unilateral pulmonary artery agenesis presenting in adulthood: a review of four cases. Clin Radiol. 2007;62:238-44.

12. Koga H, Hidaka T, Miyako K, Suga N, Takahashi N. Age-related clinical characteristics of isolated congenital unilateral absence of a pulmonary artery. Pediatr Cardiol. 2010;31:1186-90.

13. Hiramatsu T, Komori S, Okamura Y, Suzuki H, Takeuchi T, Shibuta S. Surgical correction of isolated unilateral absence of right pulmonary artery. Heart Vessel. 2010;25:353-5.

14. Stamm C, Friehs I, Zurakowski D, Scheule AM, Moran AM, Lock JE, et al. Outcome after reconstruction of discontinuous pulmonary arteries. J Thorac Cardiovasc Surg. 2002;123:246-57.

15. Welch K, Hanley F, Johnston T, Cailes C, Shah MJ. Isolated unilateral absence of right proximal pulmonary artery: surgical repair and follow-up. Ann Thorac Surg. 2005;79:1399-402.

16. Krammoh EK, Bigras J-L, Prsa M, Lapierre C, Miró J, Dahdah NS. Therapeutic strategies in children with an isolated unilaterally absent proximal pulmonary artery. Pediatr Cardiol. 2010;31:607-10.

17. Presbitero P, Bull C, Haworth SG, de Leval MR. Absent or occult pulmonary artery. Br Heart J. 1984;52:178-85.

18. Kim GB, Ban JE, Bae EJ, Noh CI, Kim WH, Lee JR, et al. Rehabilitation of pulmonary artery in congenital unilateral absence of intrapericardial pulmonary artery. J Thorac Cardiovas Surg. 2011;141:171-8.

19. Trivedi KR, Karamlou T, Yoo S-J, Williams WG, Freedom RM, McCrindle BW. Outcomes in 45 children with ductal origin of the distal pulmonary artery. Ann Thorac Surg. 2006;81:950-7.

20. Murphy DN, Winlaw DS, Cooper SG, Nunn GR. Successful early surgical recruitment of the congenitally disconnected pulmonary artery. Ann Thorac Surg. 2004;77:29-35.

21. Roofthooft MTR, Douwes JM, Vrijlandt EJLE, Berger RMF. Frequency and prognostic significance of hemoptysis in pediatric pulmonary arterial hypertension. Am J Cardiol. 2013;112:1505-9.

22. De Mello Junior WT, Coutinho Nogueira JR, Santos M, Pelissari França WJ. Isolated absence of the right pulmonary artery as a cause of massive hemoptysis. Interact Cardiovasc Thorac Surg. 2008;7:1183-5.

23. Akakabe Y, Kawasaki T, Kuribayashi T, Sugihara H. Unilateral absence of pulmonary artery. Clin Cardiol. 2009;32:E72.

24. Hamdan MA, Meshham YA, Najm HK. Successful one-stage repair of unilateral agenesis of pulmonary artery. Pediatr Cardiol. 2005;26:724-6.

25. Moreno-Cabral RJ, McNamara JJ, Reddy VJ, Caldwell P. Unilateral absent pulmonary artery: surgical repair with a new technique. J Thorac Cardiovasc Surg. 1991;102:463-5.

26. Kosaka Y, Kurosawa H, Hoshino S, Shin'oka T, Isomatsu Y, Tsuji Y. Surgery for unilateral absence of pulmonary artery using autologous tissue. Ann Thorac Surg. 2003;76:1281-3.

27. Cox D, Quinn R, Moran A, Donnelly J. Ductal origin of the pulmonary artery in isolation: a case series. Pediatr Cardiol. 2010;31:997-1001.

28. Imanaka K, Shimizu S, Matsumoto J, Hashizume K, Tsuchiya K, Takemura T. Unilateral absence of pulmonary artery and ventricular septal defect in an infant. Ann Thorac Surg. 1998;66:251-2. 